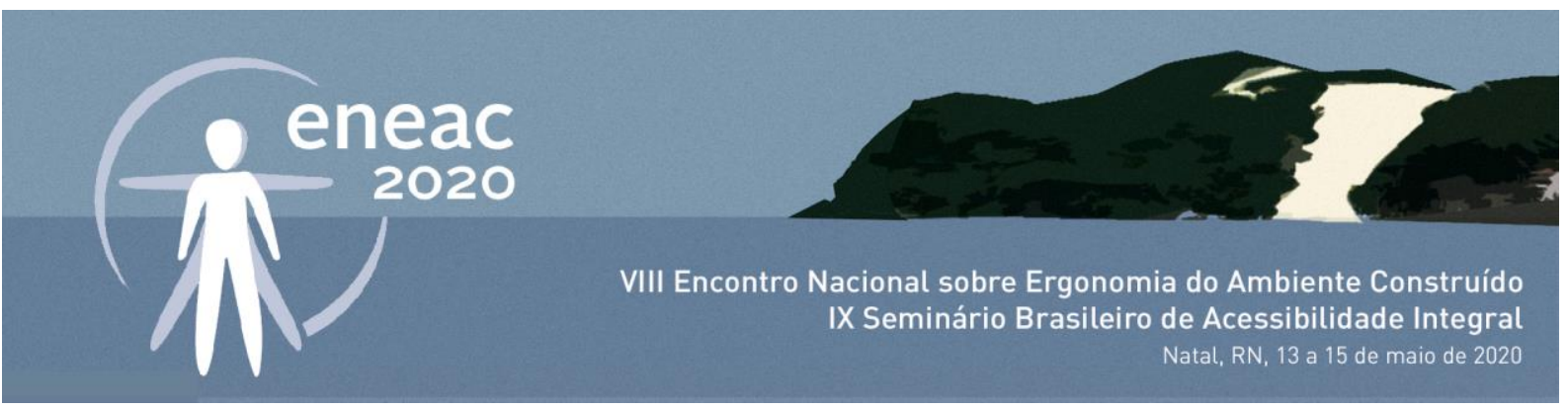

\title{
Análise do ambiente sociocultural das escolas públicas de Maceió, Alagoas
}

\author{
Social and cultural climate analysis at public schools of Maceió, \\ Alagoas
}

\author{
THAISA SAMPAIO SARMENTO \\ Arquiteta e Urbanista, Mestre em Arquitetura e Urbanismo, Doutora em Design, e-mail: \\ thaisa.sampaio@fau.ufal.br \\ WEMILLY SILVA SOARES \\ Graduanda em Design, e-mail: wemilly.ssoares@gmail.com \\ MARIA AMANDA ALVES DOS SANTOS \\ Graduanda em Design, e-mail: amandadesign96@gmail.com \\ HELOISE HELLEN NASCIMENTO SILVA \\ Graduanda em Design, e-mail: heloisehns@gmail.com
}

\section{RESUMO}

A escola é o principal lugar formador de cidadãos, no qual os estudantes são preparados para enfrentar o mundo do trabalho. A preparação dos jovens envolve tanto o desenvolvimento de conhecimentos, como aprender a se relacionar com os pares e professores. Este artigo apresenta uma análise do ambiente social e cultural de seis escolas estaduais localizadas em Maceió, Alagoas, utilizando dados do Projeto PIBIC/UFAL 2019 - 2020 - Análise de Ambientes Educacionais de Escolas Públicas de Alagoas - Considerações sobre aspectos sociais, culturais e ambientais. As coletas foram realizadas entre novembro e dezembro de 2019, e participaram 124 estudantes de ensino fundamental e médio de escolas públicas. Os resultados apresentados caracterizam o perfil social e cultural desse grupo de jovens em processo de formação, e descrevem como se relacionam com os pares e com o ambiente da escola. As considerações finais apontam para medidas que devem ser consideradas para intervenção física e de gestão do ambiente da escola, para que sejam ambientes mais agradáveis, tecnológicos e acolhedores, visando uma educação com recursos digitais, no contexto do século XXI.

PALAVRAS-CHAVE: Ambiente escolar, educação pública, percepção ambiental. 


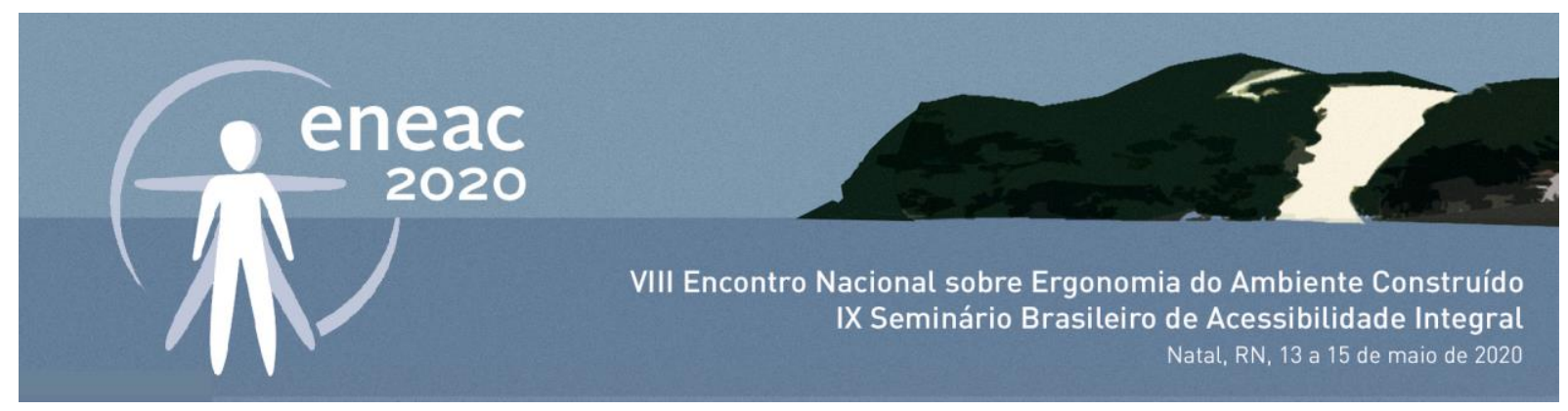

\section{ABSTRACT}

The school is the main place of citizens elaboration, in which students can develop knowledge, learning how to be in a social relation with peers and teachers, and to get a preparation to face the world of work. This article presents an analysis of social and cultural ambience of six public schools located in Maceió, Alagoas. The using data are from PIBIC/UFAL Project 2019 - 2020 - Análise de Ambientes Educacionais de Escolas Públicas de Alagoas - Considerações sobre aspectos sociais, culturais e ambientais. The data collections were done between November and December 2019, and 124 students from public schools participated as volunteers. Presented results characterized the social and cultural of youngers students' profile, in educational process, how they related to peers and the school environment. Final considerations pointed to recommendations for physical and management interventions at school environments, in order that they could be more pleasant, technological and welcoming environments, aiming achieve digital resources education context, in the context of 21st century.

KEYWORDS: School environment, public education, environment perception.

\section{INTRODUÇÃO}

De forma geral, a estrutura da escola deve abranger muito mais do que o espaço físico de salas de aula e laboratórios. O tempo em que o estudante permanece na escola é considerado positivo quando a metodologia de ensino e aprendizagem vai além do planejamento dos conteúdos presenciais e as condições físicas da escola proporcionam uma aprendizagem ampla e, aberta. É importante estabelecer conexões com o mundo fora da escola, e com as formas de comunicação e de aprendizagem em redes, superando condições de precariedade existentes.

Para compreender as formas de uso e de relacionamento entre os pares e a satisfação dos estudantes com a escola é importante utilizar técnicas de percepção ambiental e de análise do ambiente em uso. Essas ferramentas são do domínio de arquitetos, designer e psicólogos, utilizadas para compreensão do cenário físico e psicológico de cada escola.

A educação básica passa por atualizações em todo o mundo, como reflexo da vida cultural e do modo de vida cada vez mais repleto de recursos digitais. É fundamental discutirmos os espaços em que vivemos e realizamos nossas atividades cotidianas, além de pensar em como atualizar os ambientes de aprendizagem, para que estejam compatíveis com os recursos tecnológicos atuais (SARMENTO et al., 2018).

Este artigo aborda a análise do ambiente social e cultural de seis escolas estaduais localizadas em Maceió, Alagoas, utilizando dados do Projeto PIBIC/UFAL 2019 - 2020 - Análise de Ambientes Educacionais de Escolas Públicas de Alagoas - Considerações sobre aspectos sociais, culturais e ambientais. As escolas selecionadas para este artigo são localizadas no CEPA - Centro Educacional de Pesquisa Aplicada, localizado no bairro do Farol, Maceió, Alagoas.

Os dados coletados são fundamentais para compor uma caracterização plena dos usuários e das formas de uso, ocupação e convivência nos ambientes escolares típicos do nordeste do Brasil, e assim ajudar a elaborar uma caracterização, mas fiel à realidade, para embasar intervenções construtivas e também pedagógicas em espaços arquitetônicos dessas escolas e também de escolas similares. 


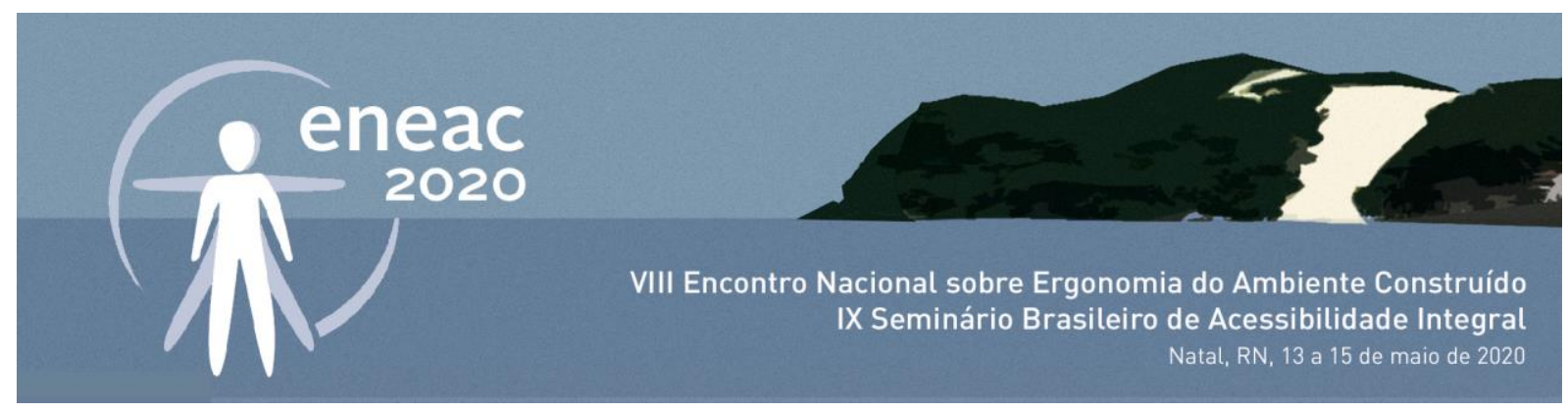

\section{METODOLOGIA}

Este artigo utilizou um desenho metodológico qualitativo dos ambientes social e cultural das escolas analisadas. Para tanto a metodologia de pesquisa utilizada baseia-se em Design Science Research DSR (DRESCH et al., 2015). Tal metodologia propõe um aprofundamento nas questões observacionais da realidade existente, para assim, desenvolver e projetar soluções para melhorar sistemas, resolver problemas, ou ainda, criar novos artefatos que contribuam para uma melhor atuação humana, seja na sociedade ou nas organizações.

O Design Science Research é aplicado em doze passos metodológicos. Este método foi utilizado com sucesso por Sarmento (2017) ao analisar o ambiente social e cultural e a ergonomia de escolas públicas em Recife, PE e de Nápoles, Itália para desenvolver uma caracterização social de grupos de estudantes de ensino médio.

Para atingir os objetivos desta pesquisa, pode-se fazer uso de técnicas de imersão (registro fotográfico, diário de bordo, elaboração de mapas de uso, observação direta) e de análise do contexto cultural e social (com aplicação de entrevistas, observação direta e etnográfica, sessões de brainstorming (PINK, 2012)). As análises apresentadas nesse artigo fazem parte da etapa abdutiva do DSR, e deverão ser complementadas com outros dados, ao longo da pesquisa em 2020.

\subsection{Recorte amostral e técnicas de coleta de dados}

Das 6 escolas participantes da pesquisa, participaram como voluntários cerca de 124 estudantes com idades que variam entre 11 a 22 anos: 45,2\% dos entrevistados têm entre 15 a 17 anos; 37,9\% têm entre 11 a 14 anos e apenas 16,9\% tem de entre 18 a 22 anos. As coletas foram realizadas no período entre 19 de novembro e 04 de dezembro de 2019, quando foram aplicados questionários com perguntas envolvendo aspectos sociais, culturais e ambientais sobre o universo vivenciado pelos estudantes.

O questionário aplicado apresentou a estrutura de quatro seções: (1) dados pessoais dos entrevistados e de suas famílias, (2) dados sobre a vivência escolar, (3) dados sobre o ambiente escolar vivenciado, e (4) dados sobre as preferências pessoais dos entrevistados para o ambiente escolar.

\section{PERCEPÇÃO AMBIENTAL EM AMBIENTE ESCOLAR}

Estudos de Kaup, Kim e Dudek (2013), Chan e Richardson (2005) e Thapa et al. (2013) apontam para a relação entre o ensino e o clima social de espaços de aprendizagem, quanto ao desempenho do estudante na escola e os impactos relativos à influência da qualidade do edifícios e dos ambientes internos de aprendizagem, corroborando com os estudos de Barrett et al. (2015), Bluyssen (2017), Tanner (2009), Powell (2015), Fraser (2015), Vasquéz et al. (2018), Souza (2018), Taylor (2009) e Cannon Design (et al., 2010).

O atual contexto cultural traz a imersão tecnológica como parte fundamental de um cenário, que se intitula cultura digital (Gomes et al., 2015), que já é percebido diariamente ao utilizarmos os recursos tecnológicos e digitais para facilitar as tarefas diárias. Segundo Sarmento e Gomes (2019) a obtenção de conforto ambiental e sociocultural no ambiente escolar se dá por meio de fatores naturais e/ou 


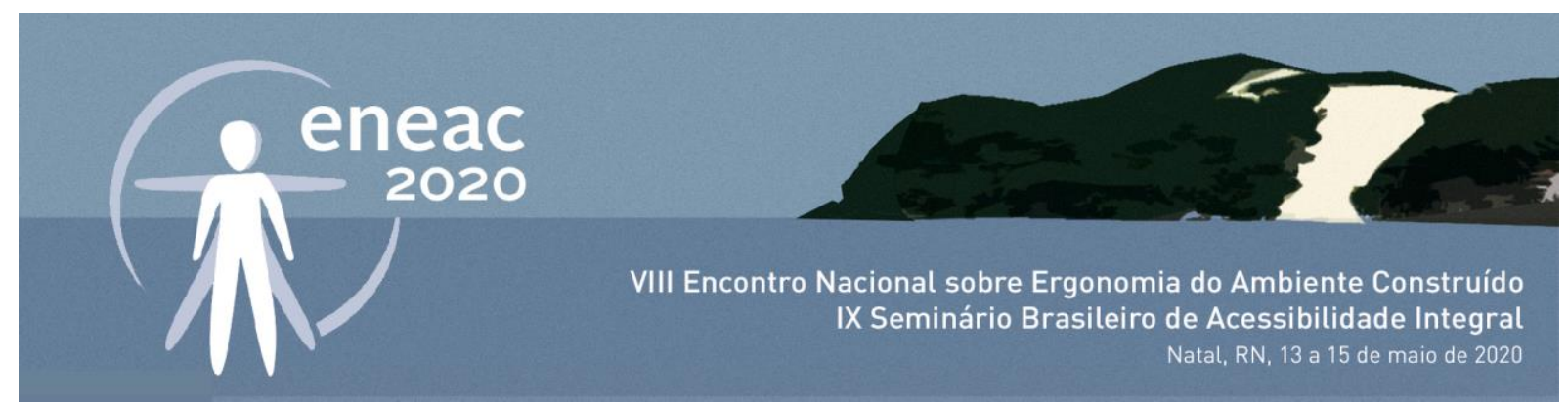

físicos e também advindos da relação interpessoal entre professor e aluno, e entre alunos, enquanto grupos.

Powell (2015) pesquisou espaços educacionais nos EUA, para identificar os comportamentos resultantes do meio físico. Sua pesquisa mostrou que uma sala inadequada, a falta de equipamentos e as condições ambientais desagradáveis evocaram respostas comportamentais em estudantes, e impactos negativos na relação entre aluno e professor. Estas respostas também apontaram para a necessidade de um esforço extra para alcançar a aprendizagem, individual e, também, coletivamente.

Rands e Gansemer-Topf (2017) utilizaram entrevistas e grupos de foco para avaliar a percepção de alunos e docentes sobre como os instrutores e alunos utilizaram um espaço para promover o aprendizado ativo (active learning), redesenhado na lowa State University e a relação entre os fatores ambientais do ambiente, com aspectos do comportamento dos alunos.

Observando-se o comportamento dos estudantes de escolas públicas brasileiras, percebe-se que há um clima social tenso entre estudantes e professores, vinculado a um baixo interesse na aprendizagem e na continuidade dos estudos. No Brasil, segundo Dorn et al. (2017) a pontuação dos alunos no PISA (Programa Internacional de Avaliação de Alunos) foi influenciada, sobretudo, por fatores ligados à motivação (29\%), à frente de características da escola $(28 \%)$, contexto socioeconômico (14\%), características do professor (14\%) e outros fatores (15\%).

A qualidade do conforto do ambiente escolar envolve aspectos ambientais que muitas vezes são conflitantes entre si. Observa-se durante o uso dos espaços escolares, em face às incompatibilidades de conforto entre a condição física existente e as necessidades reais dos usuários, muitas vezes percebem-se que os ambientes educacionais poderiam estar mais bem projetados, ou que deveriam ter sido oferecidas situações de regulação das condições de proteção, ou de melhoramento do conforto ambiental global.

\section{CARACTERIZAÇÃO DO OBJETO DE ESTUDO}

O Centro Educacional de Pesquisa Aplicada (CEPA) funciona a mais de 60 anos na cidade de Maceió, e atende a muitos estudantes. Foi totalmente reformado em 2018, passando a oferecer jardins, calçadas acessíveis, quadra esportiva e servindo de modelo para implantação da modalidade de ensino em tempo integral em escolas públicas de Alagoas. O CEPA é considerado um dos maiores complexos educacionais da América Latina, abrigando 11 escolas públicas que oferecem ensino fundamental e médio, tendo formado inúmeras gerações de maceioenses.

Do universo de 11 escolas do CEPA, 6 escolas aceitaram participar do projeto de pesquisa PIBIC/UFAL 2019 - 2020 - Análise de Ambientes Educacionais de Escolas Públicas de Alagoas - Considerações sobre aspectos sociais, culturais e ambientais, e forneceram dados para a elaboração deste artigo (ver quadro 1).

QUADRO 1: Informações principais das escolas participantes da pesquisa.

\begin{tabular}{|c|c|c|c|}
\hline ESCOLA & LOCALIZAÇÃo & $\begin{array}{c}\text { QUANTIDADE DE } \\
\text { ALUNOS }\end{array}$ & NíVEL DE ENSINO \\
\hline
\end{tabular}




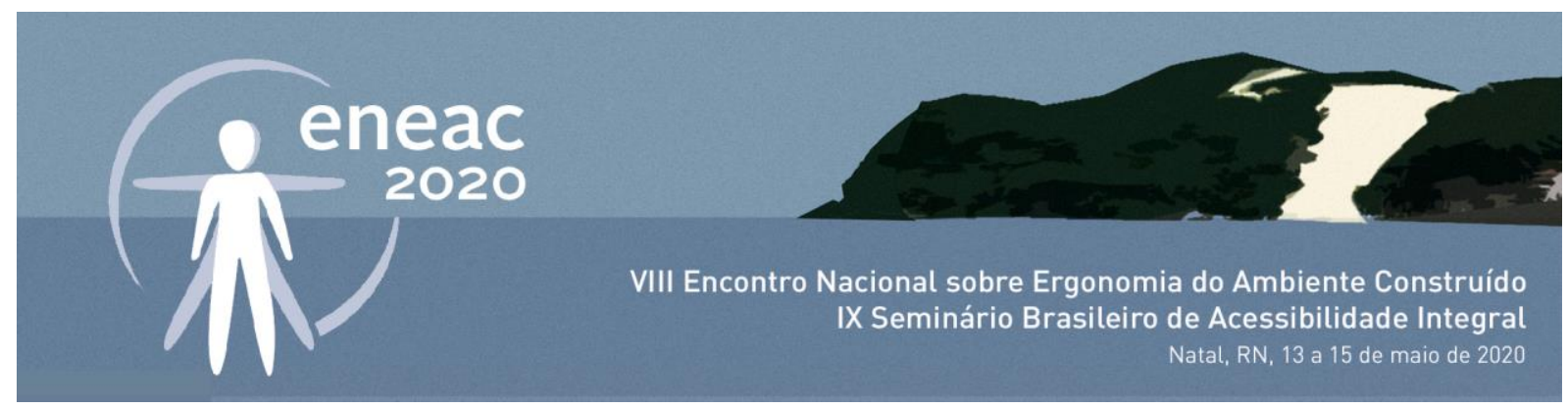

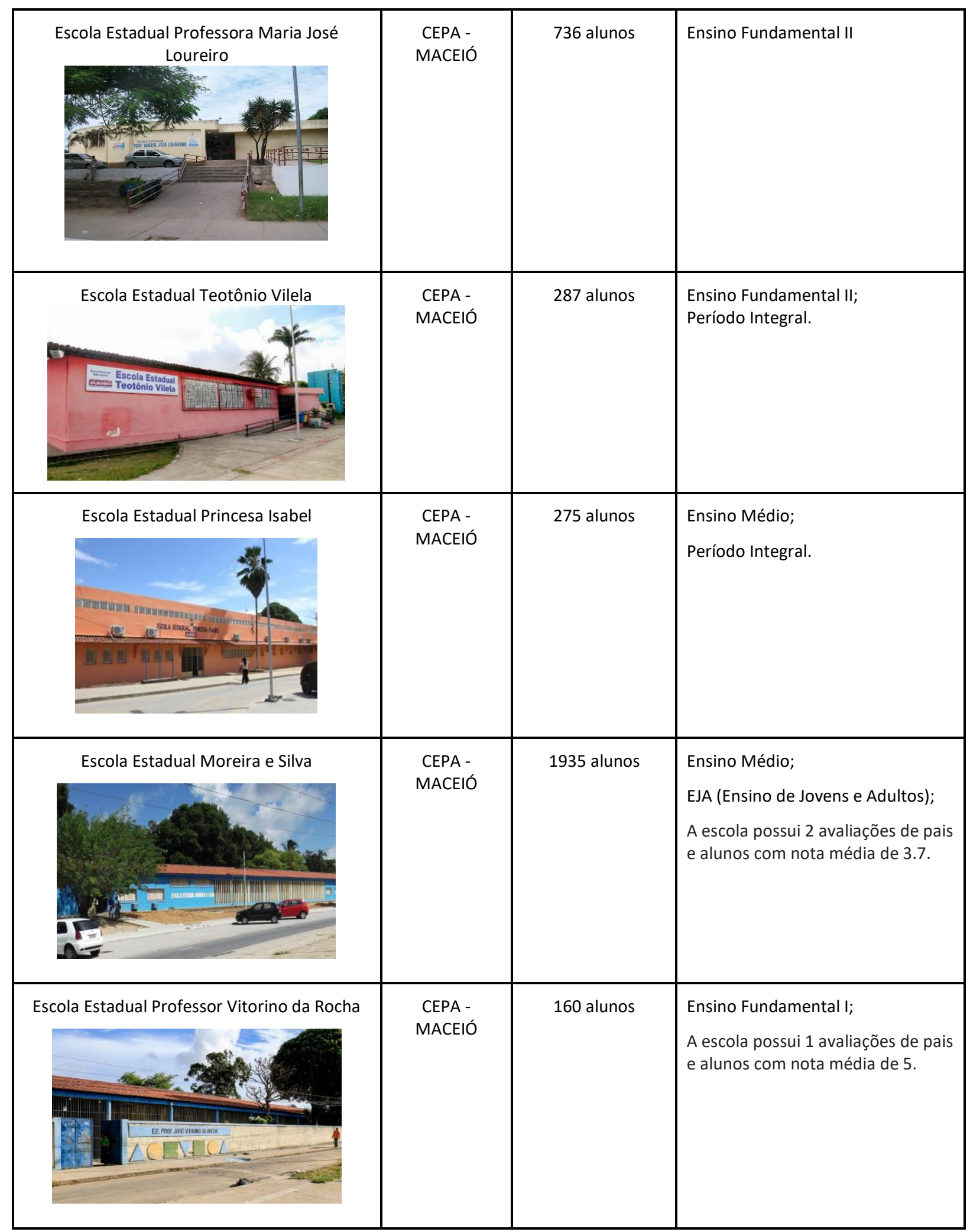



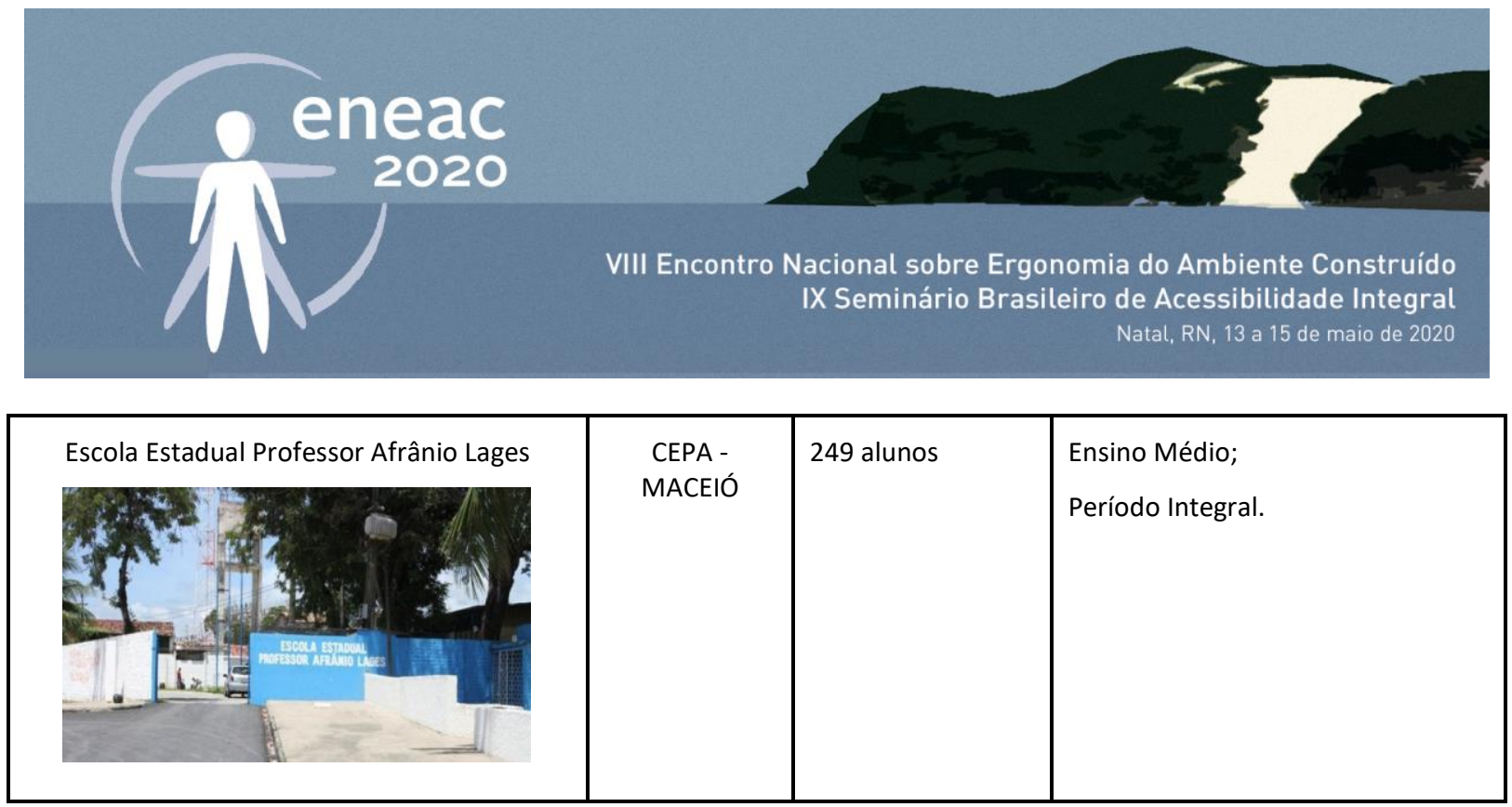

Fonte: as autoras.

\section{ANÁLISE DE DADOS OBTIDOS}

A análise de dados obtidos está dividida em três categorias para fins de compreensão geral dos contextos: dados sociais dos usuários, dados da percepção ambiental e dados das preferências dos usuários sobre os ambientes educacionais ideais.

\subsection{Dados sociais obtidos com os usuários}

Foram analisados aspectos pessoais, sobre a localização das moradias, formas de deslocamento, situação financeira familiar, uso de novas tecnologias e satisfação com ambiente da escola. A maioria dos respondentes demonstrou respostas com tendência positiva, afirmando que frequentar a escola é um caminho benéfico para seu futuro. Algumas respostas com tendência negativa demonstram a insatisfação ou desmotivação de alguns estudantes em relação a escola, ensino e/ou com o ambiente escolar, como um todo.

O relacionamento familiar implica em grande influência no desenvolvimento do indivíduo e no comportamento do estudante dentro da escola, além de implicar em seu interesse com a aprendizagem. 38,7\% dos respondentes indicaram que tem um ótimo relacionamento familiar, e existe pouca diferença na avaliação de bom e regular, sendo $29,8 \%$ para bom relacionamento e $28,2 \%$ para relacionamento considerado regular (ver Figura 1a).

Figura 1: Dados sociais familiares dos respondentes, sendo (a) relacionamento familiar e (b) situação financeira familiar.

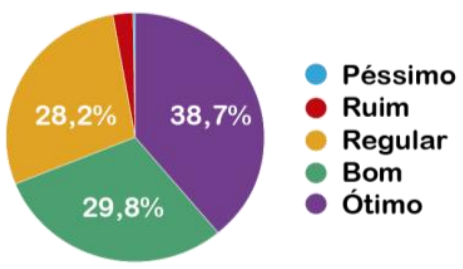

(a)

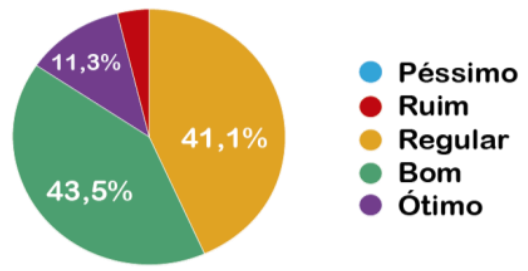

(b)

Fonte: as autoras. 


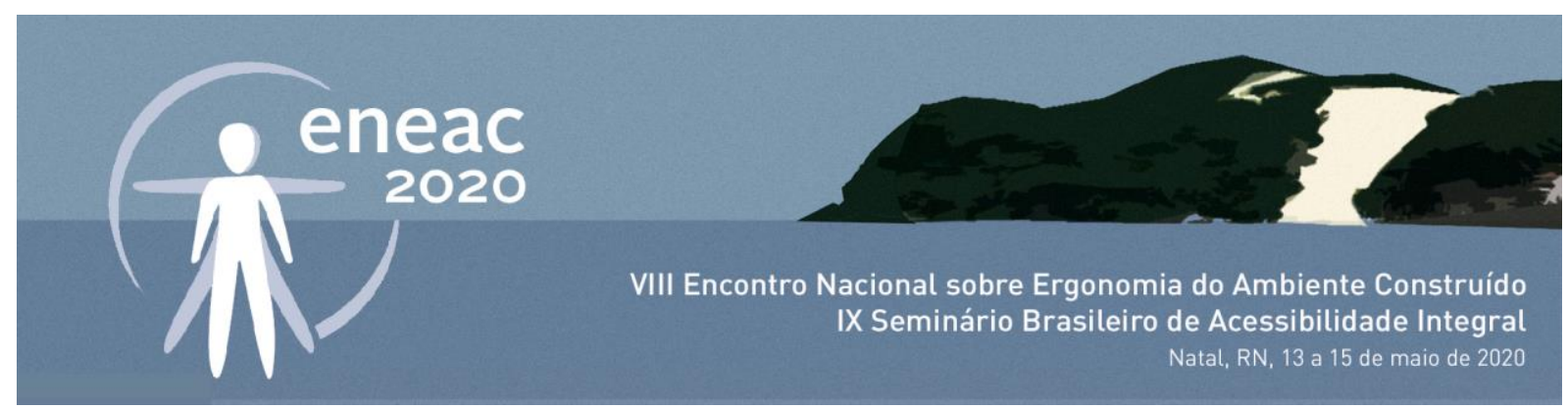

Quanto aos aspectos financeiros, pode haver relação entre bom relacionamento familiar e a condição financeira favorável, já que os dados de renda familiar apontam situação de renda familiar ótima para $11,3 \%$ dos respondente, boa para $43,5 \%$ dos respondentes e $41,1 \%$ para situação regular (ver figura $1 \mathrm{~b}$ ).

Quando questionados sobre o que gostam de fazer no tempo livre, a maioria das respostas envolvem o uso de tecnologias digitais, pois $26,6 \%$ dos respondentes responderam que costumam ficar no celular e $24,2 \%$ preferem ver filmes/séries/ouvir música (ver Figura 2). Esses dados coadunam com a resposta dada sobre a questão sobre o acesso à internet, pois $88,7 \%$ dos respondentes afirmaram ter acesso a internet, e também tem acesso ao uso de equipamentos como computador, celular e notebook (ver Figura 3). A quantidade de estudantes que têm acesso ao celular é quase $97 \%$ em comparação com os outros equipamentos tecnológicos.

Figura 2: Gráfico sobre as preferências dos estudantes em seu tempo livre.

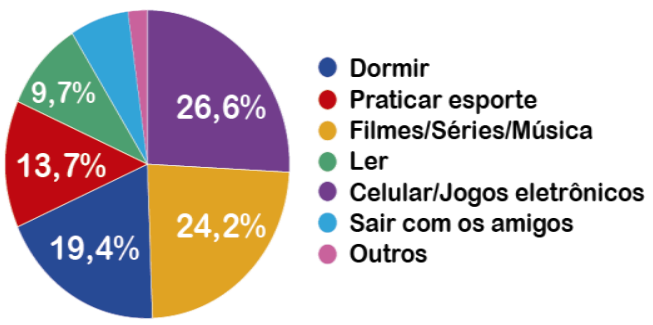

Fonte: as autoras.

Figura 3: Gráfico sobre o uso/acesso a equipamentos de tecnologia.

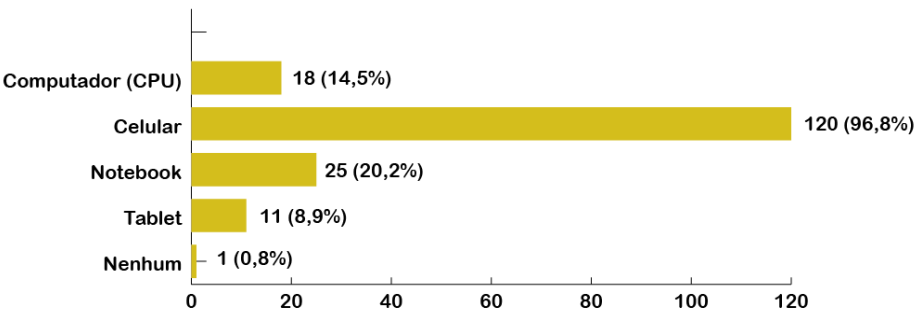

Fonte: as autoras.

Quanto ao hábito de leitura, os participantes responderam que possuem o costume de ler, mas apenas $33,1 \%$ possui o hábito de ler em casa; $41,9 \%$ lê somente na escola, possivelmente para realizar atividades durante as aulas e $9,7 \%$ dos participantes afirmaram que não leem (ver Figura 4). 


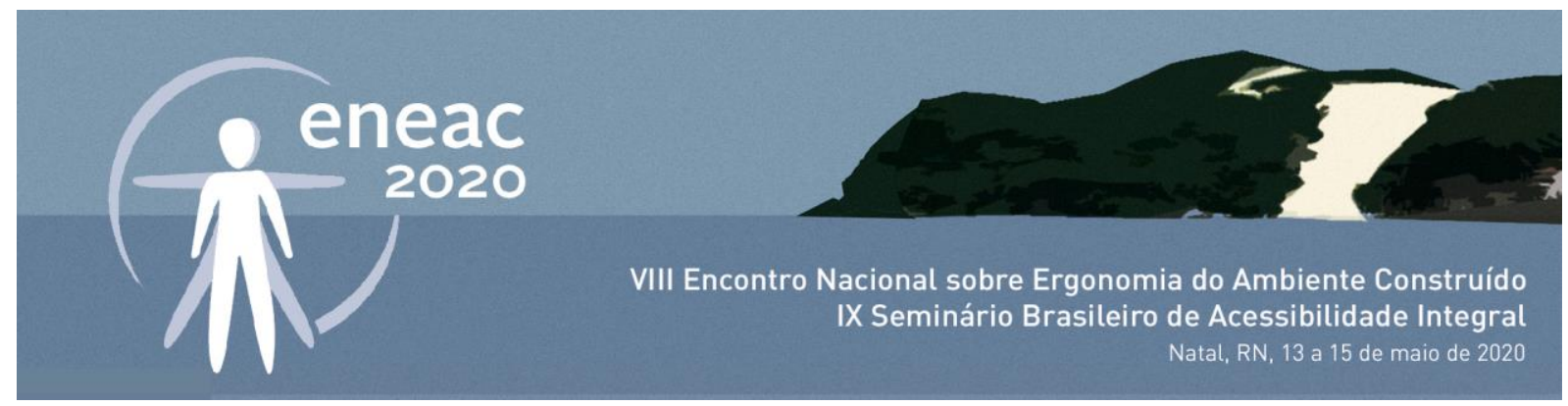

Figura 4: Gráfico sobre o hábito de leitura entre os estudantes (onde leem).

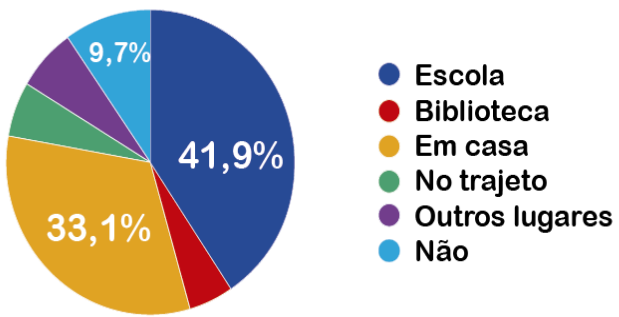

Fonte: as autoras.

\subsection{Dados obtidos sobre a percepção dos estudantes sobre a convivência social na escola que frequenta}

A compreensão dos aspectos de vivência escolar é baseada na experiência dos usuários. Cabe aos pesquisadores enxergar detalhes e situações que muitas vezes não são percebidos pelos órgãos educacionais, ou até mesmo gestores da escola.

Os estudantes foram questionados sobre a satisfação em frequentar a escola. A maioria afirmou que gostava de frequentar a escola, e as justificativas mais recorrentes foram: porque viam na escola a possibilidade de ter um futuro mais promissor. Outras respostas mostram que os estudantes gostam de ir à escola por causa das amizades que construíram nesse ambiente, outros também preferem passar mais tempo na escola, do que em casa. Uma minoria informou que não gosta, mas que sabe que ir à escola é necessário para arrumar um emprego no futuro.

Os deslocamentos dos estudantes para virem de suas casas até a escola é geralmente feito por ônibus escolar - $67,7 \%$ dos estudantes afirmam utilizar os ônibus escolares, fornecidos pela SEDUC (Secretaria de Estado da Educação de Alagoas). Existe grande variedade de origem nos quais os estudantes residem, entretanto é importante destacar que todos localizam-se na parte alta da cidade, formada por áreas periféricas, onde moram famílias de renda média e baixa.

Figura 5: Satisfação dos estudantes sobre a maneira como os professores ministram as aulas (a) e relacionamento com a turma (b).

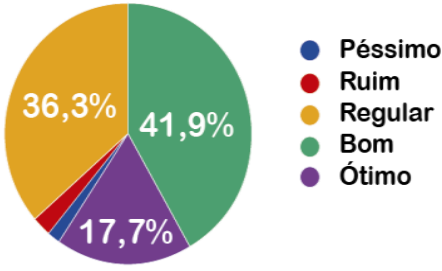

(a)

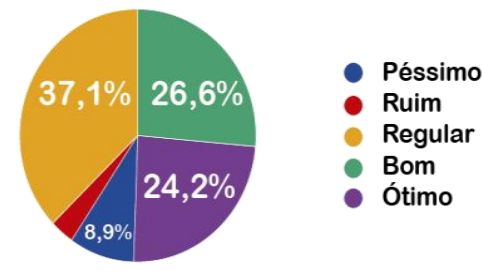

(b)

Fonte: as autoras.

Quando questionados sobre a segurança do percurso que eles fazem de sua moradia até a escola, a maioria dos respondentes demonstraram insegurança no percurso, tal resultado demonstra os riscos diários com que eles convivem, entre assaltos, furtos recorrentes. 


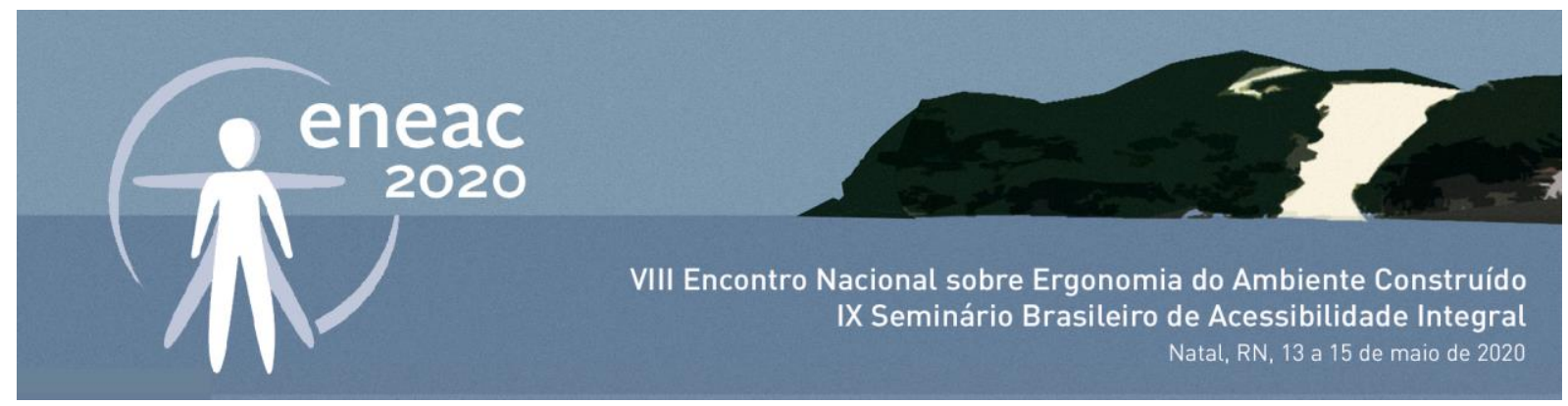

Quando questionados sobre a satisfação com a forma como os professores ministram as aulas, a maioria dos respondentes apresentou tendência positiva, entre bom (41,9\% das respostas), regular (36,3\% das respostas) e ótimo ( $17,7 \%$ das respostas) (ver Figura $5 a)$.

Com relação a percepção deles sobre o relacionamento social dentro da sua turma, houve uma divisão equilibrada das respostas. Cerca de $50 \%$ afirmou que o relacionamento com os colegas é bom (para $26,6 \%$ dos respondentes) e ótimo (para $24,2 \%$ dos respondentes). No entanto, a outra metade dos respondentes afirmou que o relacionamento com os colegas é de tendência negativa, sendo $37,1 \%$ para regular, $8,9 \%$ para péssima e cerca de $4 \%$ para ruim (ver Figura $5 b$ ). Ter relacionamentos de amizade e confiança entre os alunos é um ponto bastante positivo e importante no processo de ensino e aprendizagem, pois isso contribui para que o processo de aprendizagem seja natural, e que possa haver compartilhamento de saberes.

Sobre o interesse na aula, a maioria relatou a preferência por aulas mais dinâmicas, aulas práticas, onde o ensino não se limitasse apenas a sala de aula. Alguns respondentes relataram o desejo de poder fazer uso das tecnologias digitais durante a aula para fazer pesquisas.

Sobre relacionamentos ofensivos, ou situações de bullying, mais da metade dos respondentes afirmou que acontecem situações de bullying na escola, e que muitas vezes nada é feito para impedir tais constrangimentos.

\subsection{Dados obtidos sobre a percepção dos usuários com o ambiente escolar vivenciado}

O ambiente escolar exerce grande influência no complexo processo de ensino e aprendizagem. A definição da instituição escolar ultrapassa a compreensão de um edifício de salas de aula, cercados por muros, onde há quadras, pátio e refeitórios, mas, entende-se que a escola é associada às intensidades vivenciadas no lugar em que ocorrem, através da conexão entre localidades, materialidades, socialidades e outros elementos constituintes do fazer educacional.

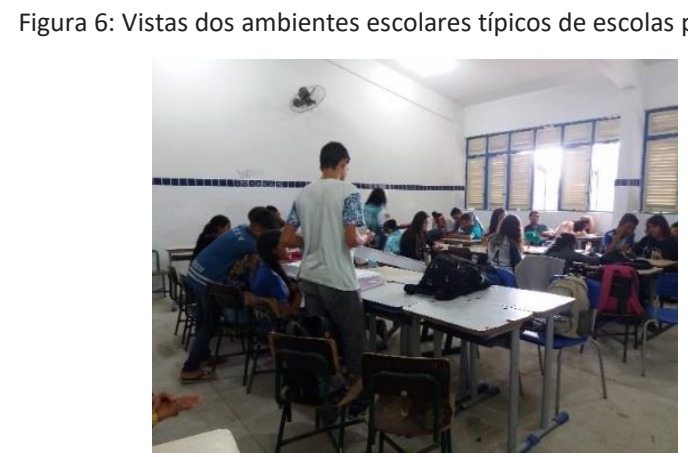

(a)

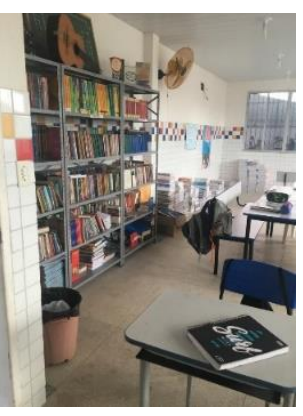

(b)

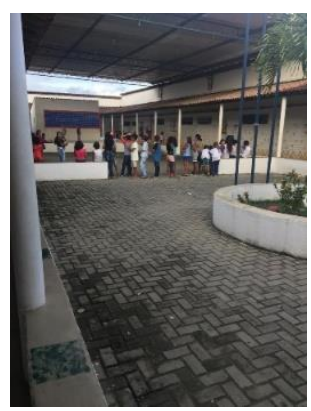

(c)

Fonte: as autoras.

Quando questionados sobre a percepção que têm da sala de aula, muitos alunos responderam que acham o ambiente bom ou ótimo (Ver Figura 6a). De acordo com os respondentes, em sua maioria, as salas são ventiladas, limpas e confortáveis. No entanto houve respostas negativas também, principalmente quanto a limpeza e a ventilação, e por conseguinte isso acaba afetando a percepção de conforto global. 


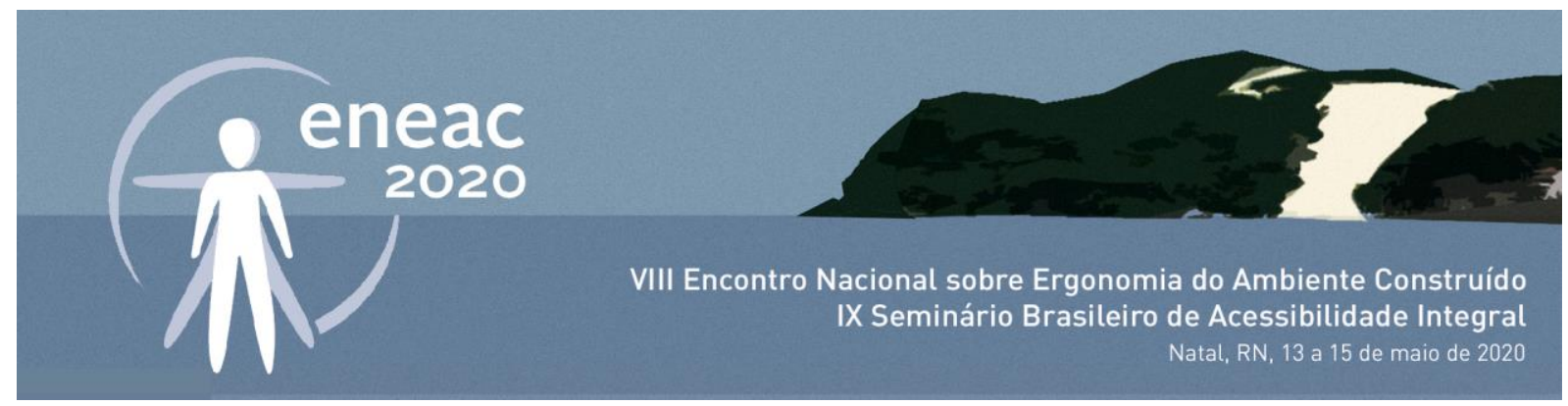

A maioria dos alunos afirmaram não frequentar a biblioteca (Ver Figura 6b) das escolas com regularidade, embora ache um espaço legal, onde há conforto e silêncio. Outros disseram que é um ambiente mal ventilado e empoeirado. Um dos respondentes afirmou não frequenta a biblioteca com assiduidade porque o local só é aberto em algumas ocasiões. A maioria dos respondentes afirmou não frequentar o laboratório de informática. Em algumas escolas existe o espaço físico do laboratório de informática, mas não há computadores no ambiente. Na Escola Teotônio Vilela, por exemplo, o espaço é usado como sala de vídeos. Em outras escolas os alunos só têm acesso ao local se forem acompanhados por algum professor. O laboratório de ciências é outro espaço pouco frequentado. Os respondentes afirmaram que este laboratório é satisfatório, outros acham que deveria ter mais investimentos na estrutura. Durante os intervalos os lugares que mais são frequentados pelos alunos são: pátio (ver Figura 6c), sala e a quadra de esportes (ver Figura 7, para a proporção das respostas obtidas).

Figura 7: Ambientes onde os estudantes costumam ficar durante os intervalos.

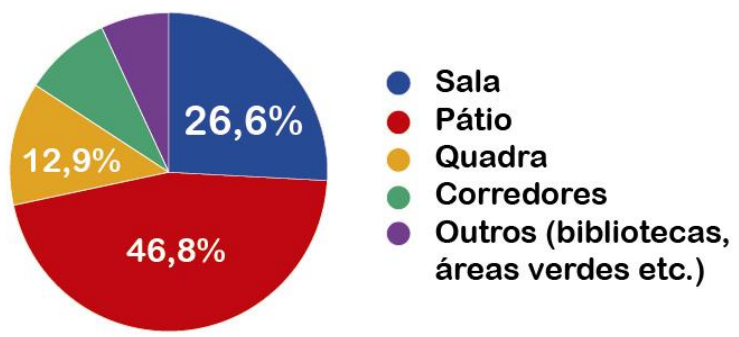

Fonte: as autoras.

Quanto à segurança pessoal, as respostas mostraram que a sensação de insegurança é predominante. Numa escala de 5 pontos, onde 1 é a pontuação correspondente à escola segura, e 5 é a pontuação atribuída a escola insegura, $32,3 \%$ dos respondentes (a maioria dos entrevistados) atribuíram nota máxima para insegurança e mais $21 \%$ dos respondentes atribuíram nota 4 . Nota-se que apenas $12,9 \%$ dos respondentes afirmaram sentirem-se seguros na escola. Ao serem perguntados sobre a ocorrência de roubos e furtos na escola, 55,6\% afirmou que já houve situações de roubos e furtos, $17,7 \%$ afirmou que não tem certeza e apenas $26,6 \%$ dos respondentes afirmaram que nunca souberam ou vivenciaram situações de roubos ou furtos.

\subsection{Dados obtidos sobre as preferências dos estudantes para um ambiente escolar ideal ou melhor}

Sobre a idealização de um ambiente escolar mais agradável, os estudantes foram questionados sobre quais atividades gostariam de desenvolver na escola, a fim de melhorar ou complementar sua aprendizagem. A Figura 8 mostra as respostas mais recorrentes. A maioria das respostas obtidas foram: usar WI-FI ( $76,6 \%$ dos respondentes), descansar ( $54 \%$ dos respondentes) e jogar ao computador (50,8\% dos respondentes). 


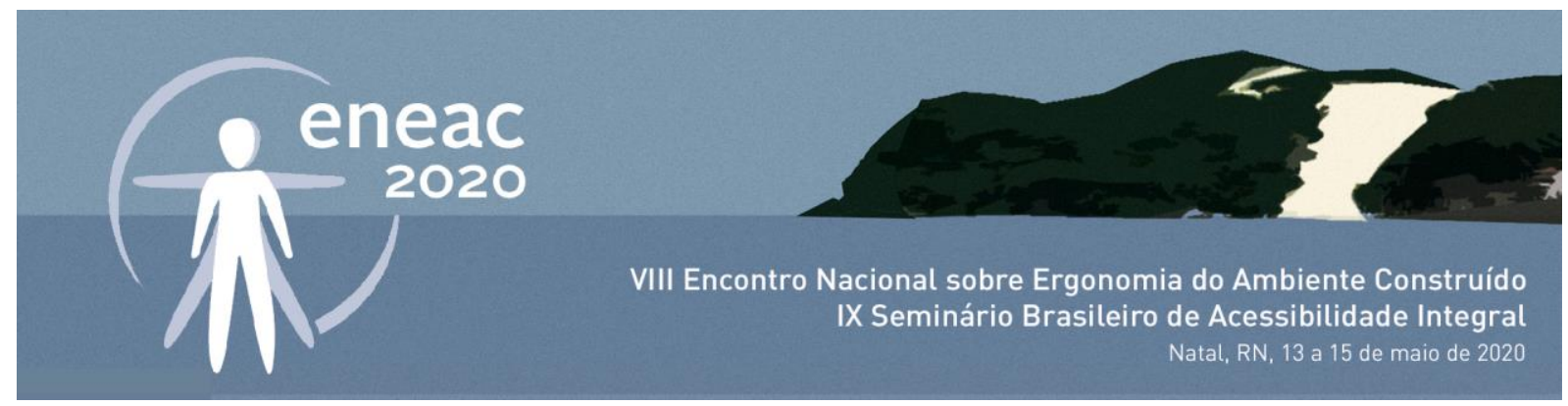

Figura 8: Atividades apontadas pelos estudantes como mais desejadas de fazerem na escola.

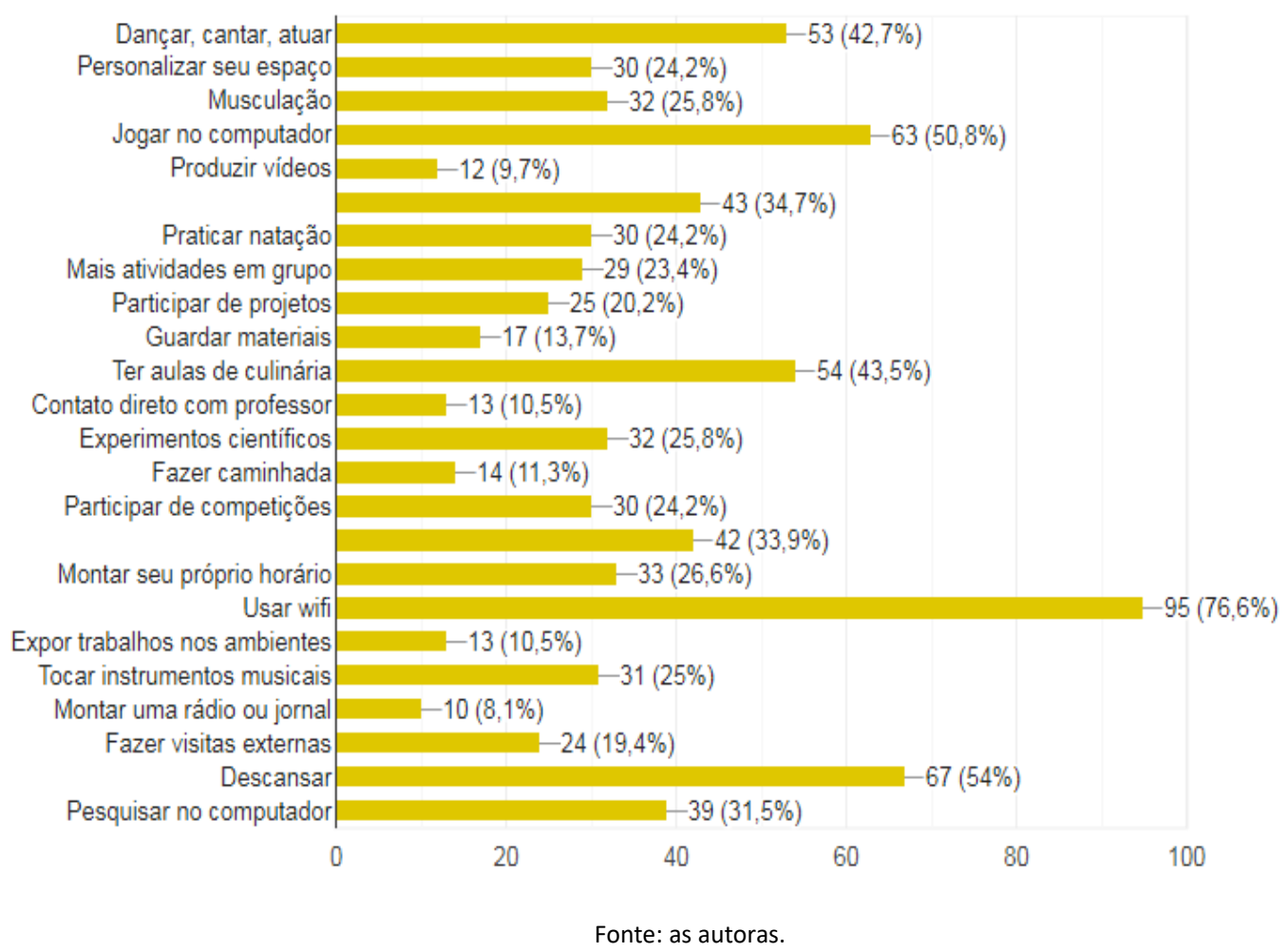

O Quadro 2, a seguir mostra as respostas obtidas com estudantes sobre conceitos e preferências para os ambientes de aprendizagem que desejariam utilizar. Destacam-se os principais conceitos desejados: ambiente iluminado, amplo e espaçoso, criativo, colorido, com vegetação, aberto, calmo e relaxante.

Quadro 2: Conceitos ambientais desejados para o ambiente escolar ideal.

\begin{tabular}{|c|l|c|}
\hline Requisito & Parâmetro & Preferência \\
\hline $\begin{array}{c}\text { Luminosidade do ambiente } \\
(113 \text { respostas) }\end{array}$ & Bem iluminado & $62,8 \%$ \\
\cline { 2 - 3 } & Pouca luz & $37,2 \%$ \\
\hline $\begin{array}{c}\text { Tamanho do ambiente } \\
(100 \text { respostas })\end{array}$ & Amplo e espaçoso & $77 \%$ \\
\cline { 2 - 3 } & Compacto & $23 \%$ \\
\hline $\begin{array}{c}\text { Organização dos móveis } \\
(102 \text { respostas) }\end{array}$ & Tradicional e organizado & $59,8 \%$ \\
\cline { 2 - 3 } & Descontraído e dinâmico & $40,2 \%$ \\
\hline
\end{tabular}




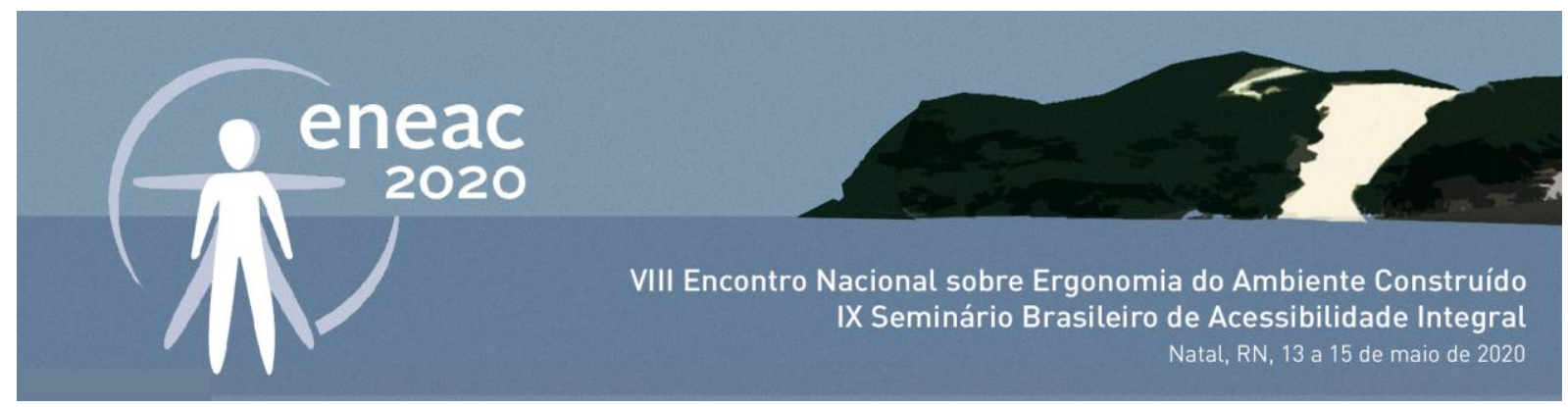

\begin{tabular}{|c|c|c|}
\hline \multirow{2}{*}{$\begin{array}{l}\text { Estilo do Ambiente } \\
\text { (104 respostas) }\end{array}$} & Simples & $39,4 \%$ \\
\hline & Criativo & $60,6 \%$ \\
\hline \multirow{2}{*}{$\begin{array}{l}\text { Cores do ambiente } \\
\text { (103 respostas) }\end{array}$} & Só uma cor & $42,7 \%$ \\
\hline & Colorido & $57,3 \%$ \\
\hline \multirow{2}{*}{$\begin{array}{l}\text { Vegetação no ambiente } \\
\text { (106 respostas) }\end{array}$} & Com vegetação & $68,9 \%$ \\
\hline & Sem vegetação & $31,1 \%$ \\
\hline \multirow{2}{*}{$\begin{array}{l}\text { Amplitude do ambiente } \\
\text { (103 respostas) }\end{array}$} & Aberto & $82,5 \%$ \\
\hline & Reservado & $17,5 \%$ \\
\hline \multirow{2}{*}{$\begin{array}{l}\text { Sensação que o ambiente provoca } \\
\text { (117 respostas) }\end{array}$} & Calmo e relaxante & $62,4 \%$ \\
\hline & Energético & $37,6 \%$ \\
\hline
\end{tabular}

Fonte: as autoras.

Compilando as informações mais relevantes para o perfil de usuários estudado, podemos sintetizar um perfil médio de estudante em escola pública em Maceió, e das preferências mais recorrentes, para elaborar uma caracterização geral de usuários. Desta forma, espera-se que esta informação possa oferecer subsídios para intervenções em escolas na região, e assim procurar atender satisfatoriamente os usuários desta faixa etária.

\section{RESULTADOS CONSOLIDADOS SOBRE OS ESTUDANTES PESQUISADOS}

Os resultados desta pesquisa apontaram para a seguinte caracterização social: os estudantes de escolas públicas de Maceió apresentaram ter um relacionamento familiar de tendência positiva (acima de 68\% dos respondentes), com renda familiar considerada na maioria satisfatória (acima de $54 \%$ dos respondentes). Quando não estão na escola, os estudantes preferem atividades ligadas a tecnologia como: jogos eletrônicos e/ou assistir filmes e séries (acima de $50 \%$ dos respondentes), e a grande maioria dos jovens têm celular (smartphone) - cerca de $96 \%$ dos respondentes. Os jovens afirmaram que leem somente na escola, para fins de estudo dirigido (cerca de $42 \%$ dos respondentes), demonstrando ampla preferência por atividades ligadas a recursos digitais.

Com relação à escola, os jovens consideram satisfatória a forma dos professores ministrarem aulas (acima de 59\% dos respondentes) e apresentaram relacionamento bom entre os pares (para acima de $50 \%$ dos respondentes), mesmo relatando ter conhecimento de situações de bullying, de assaltos e furtos, e demonstrarem sentir-se inseguros no ambiente escolar vivenciado. 


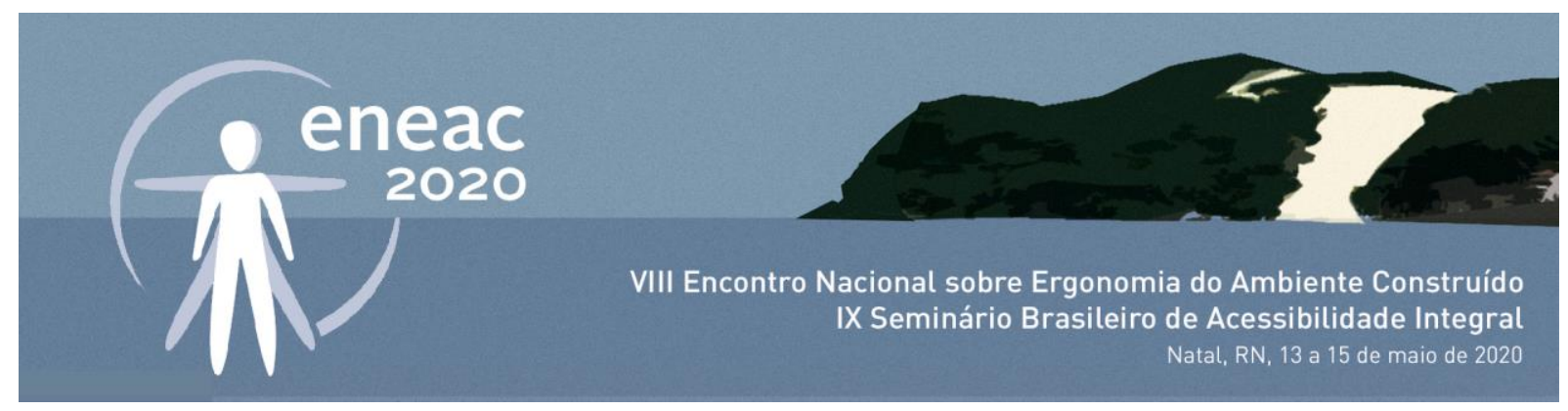

Enquanto estão na edificação escolar, os estudantes permanecem mais tempo no pátio, na sala de aula ou na quadra, em se tratando de reformas e readequações, estes ambientes deveriam ser o foco de adequações para melhorias em conforto físico e psicológico, já que cerca de $53 \%$ dos respondentes afirmaram se sentir inseguros no ambiente escolar, mesmo havendo muitas grades, portões e controle rígido por parte da gestão escolar.

Os respondentes afirmaram ainda que no ambiente escolar ideal, gostariam de ter livre acesso ao WI-FI (cerca de $76 \%$ dos respondentes afirmaram este desejo), além de também desejaram usar computadores da escola para jogar e pesquisar na internet. Interessante também destacar o desejo por atividades de descanso, já que $54 \%$ dos respondentes apontaram necessidade de ter locais para descanso e convivência (atividades que podem ser realizadas em pátios, jardins e salas de descanso). Se pudessem elencar aspectos desejados para os ambientes escolares, as características mais desejadas são: luminosidade, amplitude, estimulante para a criatividade, com vegetação no entorno próximo, em espaço aberto ao exterior, calmo e relaxante.

\section{CONSIDERAÇÕES FINAIS}

As mudanças comportamentais dos estudantes de hoje quebraram formas de conduta disciplinares e conquistaram a fusão entre trabalho e ócio, a fim de proporcionar um clima social mais aberto a inovações, e uma liberdade de relacionamento melhor com o professor, ou com a gestão da escola, podendo gerar dados mais satisfatórios com relação ao rendimento escolar, com questões de identidade e cuidado com os equipamentos e mobiliário, e sentimento de bem estar geral.

No ambiente escolar, deve-se pensar em estimular mais a criatividade e o prazer: no circuito produtivo contemporâneo busca características antes combatidas, como a originalidade associada a certa espontaneidade inventiva, e capacidade de mudança e adaptação, portanto a espontaneidade, a personalização dos espaços e objetos, a variedade de formas de fazer e de aprender assumem um valor social e psicológico favorável à aceitação da pluralidade, da diversidade e da criatividade no âmbito da escola.

Dentro dos arranjos espaciais para ambientes de aprendizagem, sugere-se dar muita atenção à concessão de superfícies de trabalho flexíveis, sejam individuais ou agrupadas, de convivência e de armazenamento (Kaup et al., 2013). Quanto a equipamentos e devices de apoio às atividades, recomenda-se que sejam de peso leve, que permite o transporte e o manejo; de forma anatômica, relacionada com as características funcionais da mão (como por exemplo celulares), já que são equipamentos muito modernos, que suportam atividades diversas, desde que haja internet WI-FI disponível. Do ponto de vista da gestão dos recursos tecnológicos, deve-se:

- Manter a conexão com internet livre constante - WI-FI e cabeamento;

- Manter redes de comunicação e de informações online e também presencial;

- Manter sala de aula física conectada constantemente com módulo de ensino on-line para carregamento, troca e disponibilização de conteúdo; 


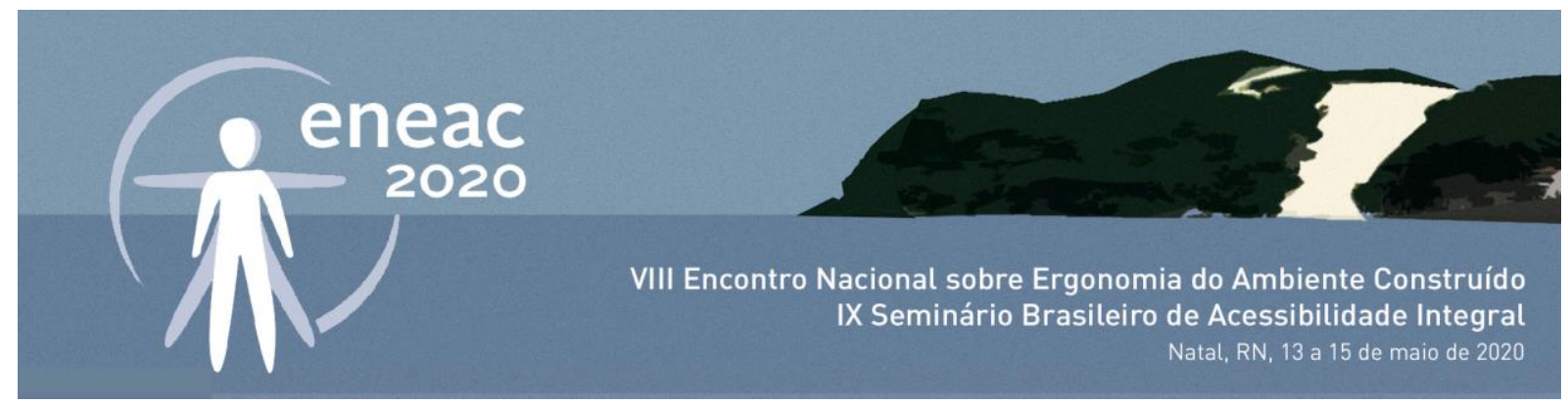

- Manter o alinhamento entre métodos de aprendizagem, recursos tecnológicos e a infraestrutura física existente (NOU, 2016);

- Permitir uso de recursos pessoais de acesso à internet - laptops e celulares, com finalidade educacional e de compartilhamento de conteúdo;

- Produzir e compartilhar conteúdo na internet.

Essas ações começaram a ser inseridas no contexto da escola pública brasileira, sendo uma mudança paulatina na forma de ensinar e de aprender. Em relação a atualizações no espaço físico da escola, Nair (2014), Kowaltowski (2010) e Guidalli (2012) sugerem recomendações gerais para intervenções em escolas existentes, com base na mudança pedagógica em busca de inclusão e respeito a diversidade na escola:

- Manter a densidade populacional confortável, evitando classes superlotadas;

- Proporcionar ambientes diversificados, preparados para atividades variadas e específicas, manuais ou com recursos digitais;

- Proporcionar armários para armazenamento de materiais pessoais, livros e para exposição dos trabalhos dos estudantes;

- Acolher com respeito as pessoas com deficiência e com dificuldade de locomoção, adequando os ambientes as recomendações técnicas de acessibilidade;

- Enquadrar a edificação nas normas de saúde e segurança vigentes em cada região do país;

- integrar o ensino presencial com tecnologias digitais, estabelecendo conexão com comunidades e redes globais;

- Permitir que as aulas aconteçam em horários flexíveis,

- Proporcionar sentimento de boas-vindas e de acolhimento social na escola, proporcionar versatilidade, agilidade e personalização da escola e de seus espaços;

- Proporcionar variações no espaço e de mobiliário, além de especificidades para as atividades de aprendizagem;

- Estimular formas de comunicação e de relacionamento social amigáveis e colaborativas, estimulando a identidade e o comportamento positivo dos usuários;

- Personalizar os espaços e ambientes escolares de modo a transparecer uma conexão com a comunidade, através da linguagem arquitetônica como expressão da pedagogia e dos valores da escola, e da comunidade a sua volta.

\section{REFERÊNCIAS}

BARRETT, P. et al. The Impact of Classroom Design on Pupils' Learning: final results of holistic, multi-level analysis. Building and Environment, v.89, n.1, p. 118-133, 2015.

BLUYSSEN, P. M. Health, Comfort and Performance of Children in Classrooms: new directions for research. Indoor and Built Environment, v.26, n.8, p. 1040-1050, 2017.

CANNON DESIGN. vs FURNITURE, BRUCE MAU DESIGN. The third teacher: a collaborative project. New York: Abrams, 2010.

CHAN, T. C.; RICHARDSON, M. D. Ins and outs of school facility management: More than bricks and mortar. Lanham, MD: Scarecrow Education, 2005. 


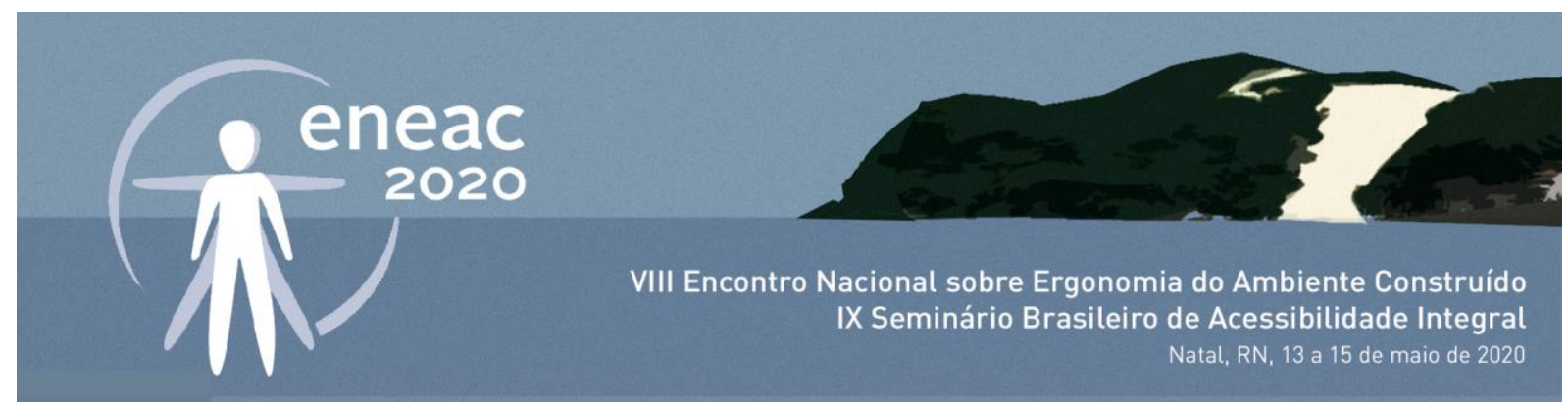

DORN, E.; ELLEN, P.; FRANK, M.; KRAWITZ, M.; CALICCHIO NETO, N.; MOURSHED, M. Fatores que influenciam o sucesso escolar na América Latina, Educação 2017, McKinsey \& Company. Diponível em: https://www.mckinsey.com/ /media/mckinsey/industries/social\%20sector/our\%20insights/what\%20drives\%20student\%2 Operformance\%20in\%20latin\%20america/fatores-qu-port.ashx. Acesso em: 02 Maio 2018.

DRESCH, A. LACERDA, D. P.; ANTUNES JUNIOR, J. A. V. Design Science Research: Método de Pesquisa para Avanço da Ciência e Tecnologia. Porto Alegre: Bookman, 2015.

GOMES, A. S. et al. Cultura digital na escola: habilidades, experiências e novas práticas. Série Professor Criativo. Recife: Pipa Comunicação, 191p. (Série professor criativo, I), 2015.

KAUP, M. L.; KIM, H.; DUDEK, M. Planning to Learn: The Role of Interior Design in Educational Settings. International Journal of Design for Learning, 4 (2), 41-55, 2013.

KOWALTOSKI, D. C. C. K. Arquitetura Escolar, o projeto do ambiente de ensino. São Paulo: Oficina de textos, 2011.

PINK, S. Situating everyday life, practices and places. London: Case ed. 2012.

POWELL, M. A. Reacting to Classroom Design: A Case Study of How Corrective Actions Impact Undergraduate Teaching and Learning. Tese de Doutorado, Lesley University, USA, 2015.

RANDS, M. L. \& GANSEMER-TOPF, A. M. The Room Itself Is Active: How Classroom Design Impacts Student Engagement. Journal of Learning Spaces, v.6, n.1, p. 26-33, 2017.

SARMENTO, T. F. C. S.; GOMES, A. S. Design de ambiente escolar para aprendizagem criativa. Recife, Pipa Comunicação, 2019.

SARMENTO, T. F. C. S.; GOMES, A. S.; MOREIRA, F. Classroom Adaptations for Blended Learning Practices. TEEM'18, 2018, Salamanca, Spain, Proceedings [...]. Salamanca, Spain, ACM, 2018. http://dx.doi.org/10.1145/3284179.3284296

SARMENTO, T. F. C. S. Modelo conceitual de ambiente de aprendizagem adequado ao Blended Learning. Tese Doutorado em Design) - Universidade Federal de Pernambuco, 260p., 2017.

SOUZA, L. N. de. Arquitetura Escolar, parâmetros de projeto e modalidades de aprendizagem. 2018. Dissertação (Mestrado em Arquitetura e Urbanismo) - Faculdade de Engenharia Civil, Arquitetura e Urbanismo, Universidade Estadual de Campinas, Campinas, 2018.

TANNER, C. K. Effects of School Design on Student Outcomes. Journal of Educational Administration, v. 47, n. 3, p. 381-399, 2009.

TAYLOR, A. P. Linking Architecture and Education: sustainable design for learning environments. New Mexico: University of New Mexico Press, 2009. 451 p.

THAPA, A., COHEN, J., GUFFEY, S., \& HIGGINS-D'ALESSANDRO, A. A review of school climate research. Review of Educational Research, 83 (3), 357-385. 2013.

VÁSQUEZ, N. G.; PEREIRA, F. O. R.; KUHNEN, A. Preferências visuais das crianças em salas de aula de educação infantil: uma aproximação experimental. Ambiente Construído, v.18, n.3, p.11-28, 2018. 